\title{
Application of SVM Models for Classification of Welded Joints
}

\author{
Dejan MARIĆ, Miroslav DUSPARA, Tomislav ŠOLIĆ, Ivan SAMARDŽIĆ
}

\begin{abstract}
Classification algorithm based on the support vector method (SVM) was used in this paper to classify welded joints in two categories, one being good (+1) and the other bad $(-1)$ welded joints. The main aim was to classify welded joints by using recorded sound signals obtained within the MAG welding process, to apply appropriate preprocessing methods (filtering, processing) and then to analyze them by the SVM. This paper proves that machine learning, in this specific case of the support vector methods (SVM) with appropriate input conditions, can be efficiently applied in assessment, i.e. in classification of welded joints, as in this case, in two categories. The basic mathematical structure of the machine learning algorithm is presented by means of the support vector method.
\end{abstract}

Keywords: Classification; Machine learning; Sound signal; SVM model; Welding

\section{INTRODUCTION}

The development of the metal industry is based on development of new technologies and on the lowering of final product price by retaining the required quality level. Welding technology, as one of the most complex technologies, requires special attention.

One of the welding processes commonly used in all metallurgical branches, and a welding process applied in this research, is the metal active gas (MAG) welding. The increase of production level, along with necessity to maintain the demanded quality, leads to the introduction of automatic and robotized welding systems. Such systems are introduced to increase productivity, so it is necessary to speed up the control of welded joints by enabling the prediction of their quality within monitoring of certain welding parameters.

Control of the welding parameters is possible to be performed with an online monitoring system that enables monitoring of main welding parameters within various welding methods (MIG/MAG, TIG, REL, etc.) [1].

However, when an error occurs, it is necessary to react timely and adequately in order to reject a faulty welded product that does not meet the required quality without performing costly and time-consuming quality control processes. Therefore, it is necessary to develop systems that will be able to perform automatic control of the welded product during the welding process itself.

Input welding parameters have a great influence on the quality of welded joints, on their mechanical properties, on microstructure, as well as on the possibility of error occurrence in the welds. Some of such input welding parameters are intensity of welding current, voltage, welding speed, the rate of wire inflow, stick out, inductance, base material, geometry structure of a joint, filler material, protective gas and its flow, operation angle, standoff distance, etc., $[2,3]$. In addition to the mentioned welding parameters, the sound of the welding process is certainly one of the features that can be used as an indication of welded joint quality.

By processing sound signals during the welding process, it is possible to detect errors and to evaluate (classify) the quality of a welded joint $[4,5,6]$.

To process the arc sound signals a variety of techniques can be used. One of the successful methods of signal processing is Hilbert-Huang transform (HHT), which included empirical mode decomposition (EMD) and Hilbert spectral analysis (HSA), also application of genetic algorithms (GA), artificial neural network (ANN) was employed to classify welded joint $[4,6,7,8]$.

In the classification of the welded joint, of good quality proved to be also some statistical data such as RMS value, arc sound kurtosis, also average arc power and arc sound frequency domain features [9, 10]. According to the authors, for evaluating quality of welded joints can be used PCA analysis too. PCA analysis is a multi-variant statistical method. (PSD) power spectral density distribution of spectrogram successfully described stability of arc welding process $[11,12]$.

It is possible to evaluate successfully keyhole geometry prediction and welding penetration using several machine languages such as extreme learning machine (ELM) technique, back-propagating neural network (BPNN) and support vector machine (SVM) [13].

The use of the SVM classification method has been shown to be of high quality for classifying multi welding defects, such as porosity, incomplete penetration, so the highest precision of the quality assurance of the welded compound can be obtained with satisfactory precision of the model [14].

The influence of welding sound and penetration in welding processes has been widely investigated. Also SVM classification model based on acoustics signal has proved to be good for the classification wire extension welding process [14].

The authors used SVM regression analysis where the kernel function is a radial basis function, whereas the activation function is a simple sigmoidal function and a model is used to identify the classification of different geometric features [13].

In addition to arc welding processes and other welding processes such as FSW - Friction Stir Welding, it is possible to build in a quality manner a SVM classification model that will meet the high accuracy criteria [7].

\section{EXPERIMENTAL SETUP}

The experimental part was performed to determine a model that would allow evaluation of the welded joint quality. Qualification of welded joints was done by a visual method (VT) to qualify welded joints in two groups, one being good welded joints $(+1)$ and the other being bad 
welded joints $(-1)$. The experiment was performed in three phases: Phase I (data collection), Phase II (post processingfiltering and data preparation), Phase III (analysis, modelling and classification). All three phases are presented in Fig. 1.

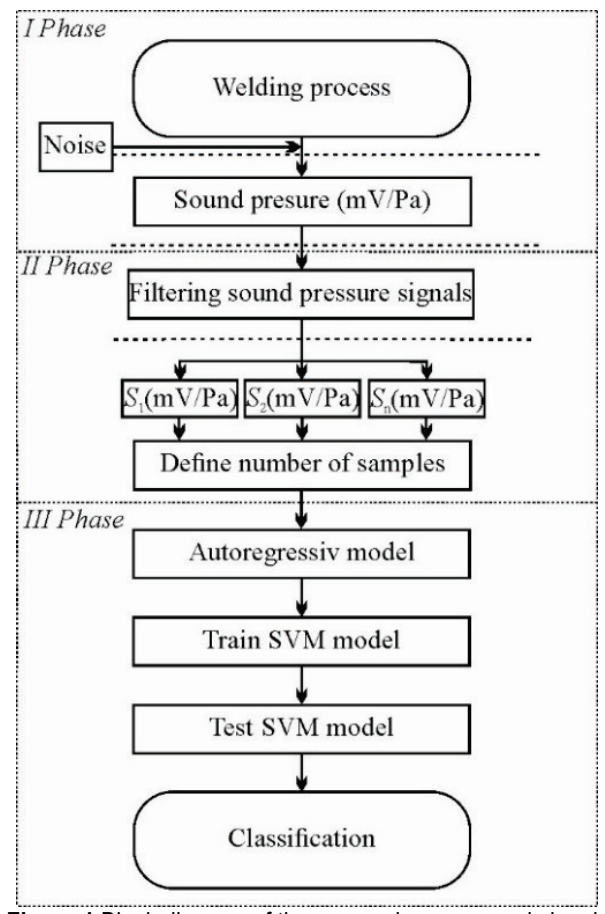

Figure 1 Block diagram of the processing arc sound signals

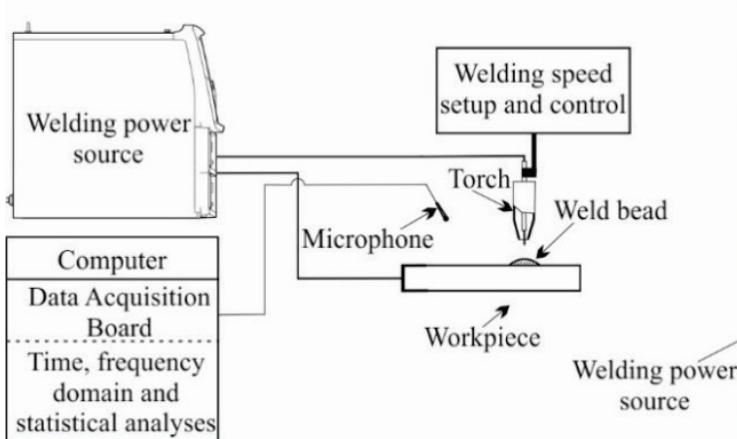

a)

Figure 2 Experimental set-up a) schematic diagram, b) the sound measurement unit
The Phase I referring to the data collection was done in laboratory conditions by using automatic experimental system, as shown in Fig. 2. The system consists of a welding part (Welbe P500L), an automatic welding process management (Fronius FTV-4) and a sound monitoring system (Data Acquisition Board -PCI-4462, PCB PIEZOTRONICS MICROPHONE with bandwidth of 5 to $70000 \mathrm{~Hz}$, and frequency response characteristic is Pressure $1,0 \mathrm{mv} / \mathrm{Pa}$ ). The system is fully automated, welding speed and control of welding process is controlled over automatic welding process management (Fronius FTV-4) which is connected to welding power source Welbe P500L and the torch is positioned in the position shown in Fig. 2. The motion of the torch and microphone (PIEZOTRONICS MICROPHONE) is synchronized. Microphone is placed at a distance of $300 \mathrm{~mm}$ from the torch. Microphone is connected to Data Acquisition Board -PCI-4462 which is used for recording the sound of the welding process. The welding was performed on plates made of $\mathrm{P} 265 \mathrm{GH}$ material in dimensions $300 \times 150 \times 10 \mathrm{~mm}$. The welding parameters were defined according to the practice, and by using the referential recommendations [2, 3]. The experimental part of this research was performed according to the central composite experiment plan, with definition of 18 experimental conditions (the condition in the centre was repeated four times).
Tab. 1 presents the factor levels determined by the experimental state matrix for the central composite experiment plan with three factors. Taking into account the geometric shape of the welded joint (penetration, penetration width, groove fill in, weld surface roughness) input parameters such as contact distance tip to work piece, wire feed speed, travel speed, welding voltage, welding current and shield gas composition have a great influence on the said geometrical shape [2]. Welding parameters used in welding experiment are welding current, welding voltage and welding speed which have the greatest influence on arc sound and also on the arc stability or metal transfer behaviour. Also input parameters have a great impact on heat input in welded joint which is in correlation with the quality of the welded joint. Welding speed has a large impact on the deposition efficiency which is also an important economic factor. Welding current and welding voltage in combination with arc sound signals can be used to monitor the welding parameters.

In addition, the main welding parameters have an impact on other quality parameters of the welded joint. A strong influence on the penetration have welding current, arc voltage and welding speed; increase in welding current increases also the penetration [15].

Table 1 Welding parameters used in welding experiment

\begin{tabular}{|c|c|c|c|}
\hline & $\begin{array}{c}\text { Voltage } \\
U / \mathrm{V}\end{array}$ & $\begin{array}{c}\text { Welding speed } \\
v_{\text {weld }} / \mathrm{cm} / \mathrm{min}\end{array}$ & $\begin{array}{c}\text { Current } \\
I / \mathrm{A}\end{array}$ \\
\hline$-1,682$ & 19 & 15 & 120 \\
\hline-1 & 21 & 25 & 152 \\
\hline 0 & 24 & 40 & 200 \\
\hline 1 & 27 & 55 & 248 \\
\hline 1,682 & 29 & 65 & 280 \\
\hline
\end{tabular}

In order to perform high quality analysis of the obtained parameters, it is necessary to record and collect appropriate amount of data. The authors [1, 16] used 
sampling frequency of $20 \mathrm{kHz}$, while the referential literature $[9,8,10,14,17]$ states $40 \mathrm{kHz}$ sampling frequency. There is also 48 sampling frequency applied $[11,18]$, however, some authors used also 25,6 kSamples/s [4]. In this experiment, samples are obtained at a rate of 20 kSamples/s.

In order to be able to analyze the recorded signal in the Phase III, it is necessary to perform postprocessing of the recorded signal (Phase II) and to remove possible disturbances that may have been recorded. The signal can be filtered in a traditional way by using traditional filters or by applying the wavelet denoising method. According to the literature recommendations, the wavelet denoising method was used in this experiment $[6,12]$.

Sound pressure signals are filtered by means of wavelet denoising filter. The smallest error was observed in the case when discrete wavelet transform (DWT) was used with wavelet db14 of level 1 and universal thresholding rule.

The recorded and filtered data were processed using the autoregressive model (AR). The autoregressive model assumes that the current dependent variable $x_{t}$ depends on the previous values and the same variable $x_{t-1}, x_{t-2}, x_{t-n}$ and on the prediction error $e_{t}$.

$x_{t}+a_{1} x_{t-1}+a_{2} x_{t-2}+a_{n} x_{t-n}=e_{t}$

The previous equation can be written as follows:

$A(q) x_{t}=e_{t}$

$A(q)$ is AR operator defined as:

$$
A(q) x_{t}=1+a_{1} q^{-1}+a_{2} q^{-2}+a_{n} q^{-n}
$$

The term $q^{-\mathrm{k}}$ is the backward shift operator:

$q^{-k} x_{t}=x_{t-k}$

In the SVM model, there is autoregression of the first and second order applied (AR(1), AR(2)). The SVM classifier developed in 1995 by Vapnik is a model used in this experiment for classification and prediction of classification of new welded joints. The SVM model finds a hyperplane that has the highest margin of class separation. The model itself has already proved as efficient in classifying welded joints, as confirmed by the authors $[7,13,14,16]$.

As the problem presented in this paper is nonseparable, there are allowed errors that are penalized, but still the surface of separation should separate classes as efficiently as possible.

The data for training of the SVM model are composed on the $N$ pairs $\left(x_{1}, y_{1}\right),\left(x_{2}, y_{2}\right), \ldots,\left(x_{n}, y_{n}\right)$ and the response surface $y_{i} \in\{-1,1\}$, under the condition that $x_{i} \in R^{p}$ [19].

The equation of hyperplane is defined as:

$w^{\mathrm{T}} x+b=0$

where: $w$ - vector of normal hyperplane; $b$ - defines the distance between the plane and the coordinate start.
The SVM model with a visible hyperplane and parallel plane (support vectors) that divide two groups of data, and that can be written using the equations:

$$
\begin{aligned}
& w^{\mathrm{T}} x+b=-1 \\
& w^{\mathrm{T}} x+b=1
\end{aligned}
$$

The distance between the supporting vectors is the $M$ margin. It should be maximized and it can be written as:

$M=\frac{1}{\|w\|}$

The problem of function maximization (8) is solved with the following condition:

$y_{i}\left(w^{\mathrm{T}} x_{i}+b\right) \geq 1$

By using the method of Lagrange multipliers and by transferring to dual formulation of Lagrangian (Wolfe) dual objective function:

$L_{\mathrm{D}}=\sum_{i=1}^{N} \alpha_{i}-\frac{1}{2} \sum_{i=1}^{N} \sum_{i^{\prime}=1}^{N} \alpha_{i} \alpha_{i^{\prime}} y_{i} y_{i^{\prime}} x_{i}^{\mathrm{T}} x_{i^{\prime}}$

optimization problem (8) and (9) can be written in the form of a convex optimization problem in terms of alpha variable.

$w=\sum \alpha_{i} y_{i} x_{i}$

and the decision function can be written as:

$$
f(x)=\operatorname{sign}\left[w^{\mathrm{T}} x+b\right]=\operatorname{sign}\left[\sum \alpha_{i} y_{i} x_{i}^{\mathrm{T}} x+b\right]
$$

where $x_{i}$ is a group of support vectors that belongs to the sub-group of the model $X$ training group and coefficients $\alpha_{i}$. Presented example is referring to the cases when vectors can be divided with hyperplane, and when this is not possible, as in the case presented in this paper, a soft margin classifier or transformation by using kernel function should be applied. Since the data obtained in the experimental part are not linearly divisible, the solution that is possible to be applied refers to introduction of the kernel function, i.e. transition to the area of greater dimension in which the data would be linearly divisible. This is enabled by transformation function $x \rightarrow \Phi(x)$.

Kernel function is directly connected with transformation of $\Phi$, within which:

$$
K\left(x_{1}, x_{2}\right)=\Phi\left(x_{1}\right)^{\mathrm{T}} \Phi\left(x_{2}\right)
$$

One of the main preconditions for using this function is to satisfy Mercer theorem. There are many kernel functions, such as dth-Degree polynomial, Radial basis, Neural network, Gaussian kernel. The Gaussian kernel was used in this paper [20]: 


$$
K\left(x_{1}, x_{2}\right)=\exp \left(-\left\|x_{1}-x_{2}\right\| 2\right)
$$

By using the kernel, the nonlinear problems are solved as linear ones (a kernel trick), and on the basis of Eq. (12) the following expression is obtained:

$$
f(x)=\operatorname{sign}\left[\sum \alpha_{i} y_{i} \Phi\left(x_{i}\right)^{\mathrm{T}} \Phi(x)+b\right]
$$

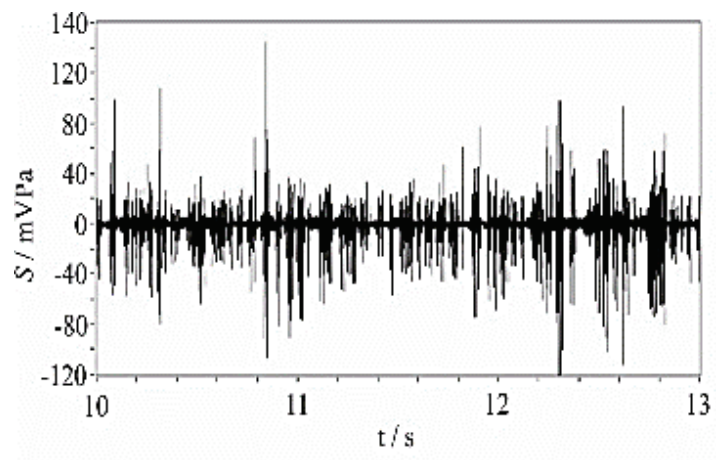

a)

\section{EXPERIMENTAL RESULTS AND DISCUSSIONS}

Fig. 3a) shows the diagram of recorded MAG welding sound without errors in welding and without filtration, while Fig. 3b) presents the same recorded signal filtered by means of the wavelet denoising method.

Changing the welding voltage or unstable arc condition also leads to changes in the welding sound. [21]

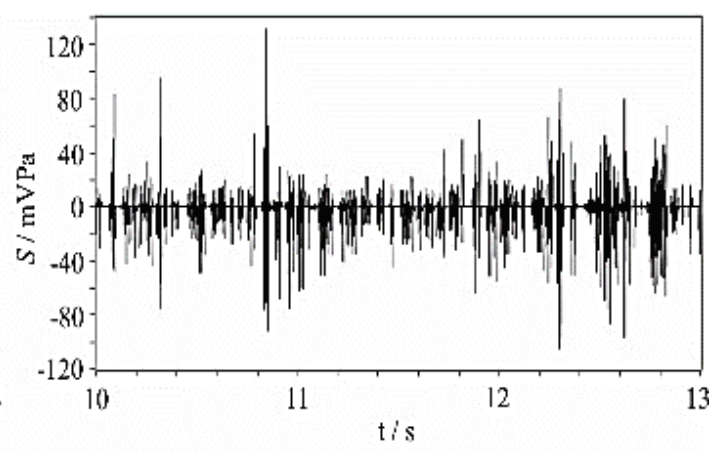

b)

Figure 3 Arc sound signals of MAG welding process a) original signal with noise, b) denoising result

Fig. 4 presents vectors marked by using the first-order autoregression on the ordinate, and the second-order autoregression on the abscissa. By entering all vectors, it is possible to create a SVM model according to previously defined rules.

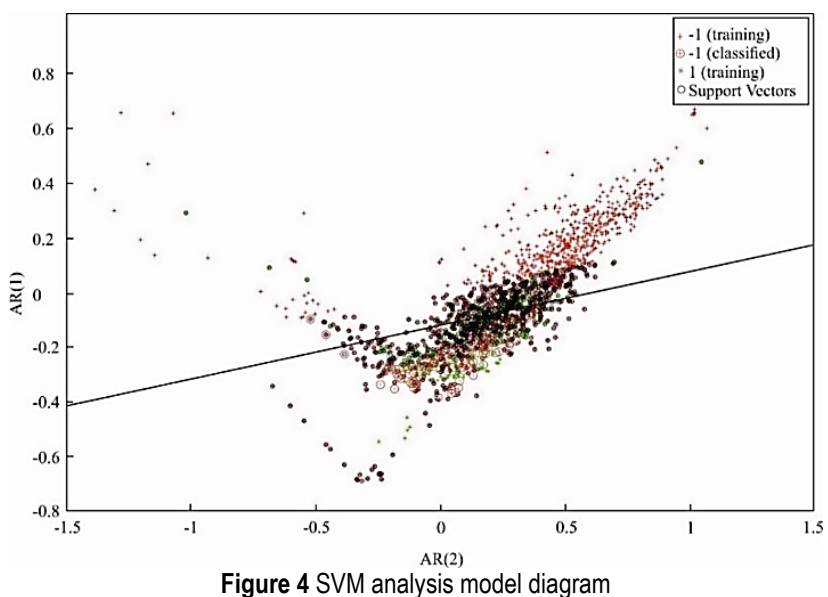

The production of the SVM model was done by processing the data in the Matlab software package, for the model execution the following parameters are used as shown in Tab. 2.

Table 2 Classifier SVM model

\begin{tabular}{|c|c|}
\hline Preset & Fine Gaussian SVM \\
\hline Kernel function & Gaussian \\
\hline Kernel scale & 0,35 \\
\hline Multiclass method & One-vs-One \\
\hline
\end{tabular}

Based on the data obtained by the SVM analysis, the authors classified new parameters, i.e. the recorded and postprocessed parameters of the recorded welding sound to determine the welded product class. If taken into account that created SVM model has a calculated precision of $84,2 \%$, as seen in Tab. 3 , this indicates that quality of a new welded joint can be precisely indicated. Furthermore, the efficiency of the created model is proven by the confusion matrix, where the number of elements on the main matrix diagonal is significantly higher than the number of elements on the side diagonal. When considering the ROC (Receiver Operating Characteristics), the model is positioned at the direction TPR $=\mathrm{FPR}$ and the AUC area is 0,77 , therefore this model can be classified as a good one.

Table 3 Results of SVM analysis for qualification of new sound signals

\begin{tabular}{|c|c|}
\hline Model Name & SVMModel \\
\hline Accuracy & $84,2 \%$ \\
\hline Prediction speed & $\sim 59000 \mathrm{obs} / \mathrm{s}$ \\
\hline Training time & $0,68333 \mathrm{~s}$ \\
\hline
\end{tabular}

Fig. 5 shows successful classification of the welded joint by using the SVM classifier. The quality of the welded joint was determined by visual control of the surface of welded joints according to EN ISO 5817 for Quality levels for imperfections (continuous undercut, overlap, sagging incompletely filled groove, spatters).

According to the EN ISO 5817 for Quality levels for imperfections on the welded joint in Fig. 5 are determined areas of poor quality $(-1)$ with imperfection (weld crater (2025), spatters (602) and excess weld metal (502)), and areas of good quality (1).
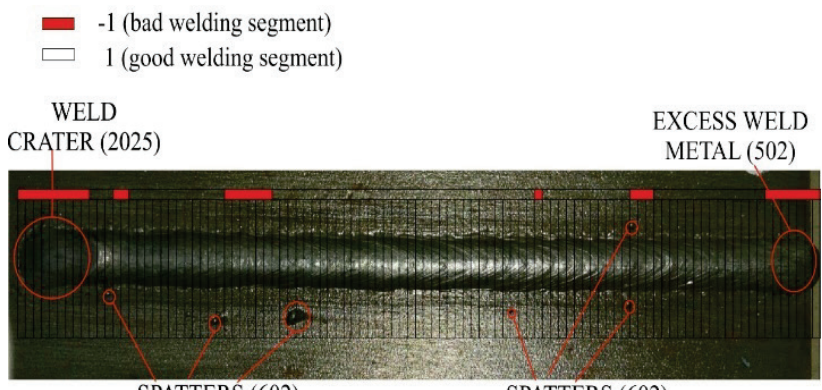

SPATTERS (602)

SPATTERS $(602)$

Figure 5 Classification of new welded joints - welded joints with bad welding areas $(-1)$, and areas of good quality (1) 


\section{CONCLUSION}

This paper presents successful classification of welded joints by using recorded sound signals and mathematical model of the support vector method. It elaborates an example of calcification of new welded joints based on recorded sound signals during MAG welding process. Main advantage of this classification model is that the model is not corrupted by background noise, all the noise has been eliminated by discrete wavelet transform (DWT), and in the case of recorded sound signals during MAG welding process in industrial environment also all the noise will be eliminated. Classification was performed at a rather high precision level of $84.2 \%$. All other good classification indicators of this model confirm that the support vector method is appropriate to be applied in the classification of welded joints. The quality is evaluated by visual control (VT) of welded joints in two categories, one being good quality welded joints $(+1)$, and the other bad welded joints $(-1)$. It is concluded that applying a method of processing welding sound signal with a quick response (wavelet denoising filter + autoregressive model + SVM) can successfully detect changes in the quality of welded joints. By combining this method with other corresponding welding parameters, such occurring changes in quality of welded joints can be efficiently corrected. According to this investigation and developed model industries that have a high degree of welding process automation can provide and accelerate the process of quality control of welded joints according to EN ISO 5817 for Quality levels for imperfections (surface defects).

\section{REFERENCES}

[1] Siewert, T., Samardžić, I., Kolumbić, Z., \& Klarić, Š. (2008). On-Line Monitoring System - An Application for Monitoring Key-Welding Parameters of Different Welding Processes. Tehnički vijesnik, 15(2), 9-18.

[2] Huanca Cayo, E. \& Absi Alfaro, S. (2001). Relationship between geometric welding parameters and optical-acoustic emissions from electric arc in GMAW-S process. Journal of Achievements in Materials and Manufacturing Engineering, 46(1), 79-87.

[3] Naidu, D. S., Ozcelik, S., \& Moore, K. L. (2003). Modeling, Sensing and Control of Gas Metal Arc Welding. AmsterdamBoston-London-New York-Oxford-Paris-San Diego-San Francisco-Singapore-Sydney-Tokyo: Elsevier.

[4] Yusof, M. F., Kamaruzaman, M. A., Ishak, M., \& Ghazali, M. F. (2016). Porosity detection by analyzing arc sound signal acquired during the welding process of gas pipeline steel. Int J Adv Manuf Technol, 89(9-12), 3661-3670. https://doi.org/10.1007/s00170-016-9343-4

[5] Čudina, M., Prezelj, J., \& Polajnar, I. (2008). Use of audible sound for on-line monitoring of gas metal ARS welding process. Metalurgija, 47(2), 81-85.

[6] Wang, J. F., Yu, H. D., Qian, Y. Z., Yang, R. Z., \& Chen, S. B. (2011). Feature extraction in welding penetration monitoring with arc sound signals. J. Engineering Manufacture, 225, 1683-1691. https://doi.org/10.1177/0954405411405108

[7] Das, B., Pal, S., \& Bag, S. (2017). Torque based defect detection and weld quality modelling in friction stir welding process. Journal of Manufacturing Processes, 27, 8-17. https://doi.org/10.1016/j.jmapro.2017.03.012

[8] Bhattacharya, S., Pal, K., \& Pal, S. K. (2012). Multi-sensor based prediction of metal deposition in pulsed gas metal arc welding using various soft computing models. Applied Soft Computing, 12(1), 498-505. https://doi.org/10.1016/j.asoc.2011.08.016

[9] Pal, K., Bhattacharya, S., \& Pal, S. K. (2010). Investigation on arc sound and metal transfer modes for on-line monitoring in pulsed gas metal arc welding. Journal of Materials Processing Technology, 210(10), 1397-1410. https://doi.org/10.1016/j.jmatprotec.2010.03.029

[10] Pal, K. \& Pal, S. K. (2010). Study of weld joint strength using sensor signals for various torch angles in pulsed MIG welding. CIRP Journal of Manufacturing Science and Technology, 3(1), 55-65. https://doi.org/10.1016/j.cirpj.2010.07.007

[11] Liu, L., Lan, H., Zheng, H., \& Jian, X. (2012). Feature extraction and dimensionality reduction of arc sound under typical penetration status in metal inert gas welding. Chinese Journal of Mechanical Engineering, 25(2), 293-298. https://doi.org/10.3901/CJME.2012.02.293

[12] Yao, P., Zhou, K., \& Zhu, Q. (2017). Quantitative evaluation method of arc sound spectrum based on sample entropy. Mechanical Systems and Signal Processing, 92, 379-390. https://doi.org/10.1016/j.ymssp.2017.01.016

[13] Wu, D., Chen, H., He, Y., Song, S., Lin, T., \& Chen, S. (2016). A prediction model for keyhole geometry and acoustic signatures during variable polarity plasma arc welding based on extreme learning machine. Sensor Review, 36(3), 257-266. https://doi.org/10.1108/SR-01-2016-0009

[14] Song, S., Chen, H., Lin, T., Wu, D., \& Chen, S. (2016). Penetration State Recognition based on the Double-SoundSources Characteristic of VPPAW and Hidden Markov Model. Journal of Materials Processing Technology, 234, 33-44. https://doi.org/doi:10.1016/j.jmatprotec.2016.03.002

[15] Mostafa, N. B. \& Khajavi, M. N. (2006). Optimisation of welding parameters for weld penetration in FCAW. Journal of Achievements in Materials and Manufacturing Engineering, 16(1-2), 132-138.

[16] Zhang, Z., Chen, H., Xu, Y., Zhong, J., Lv, N., \& Chen, S. (2015). Multisensor-based real-time quality monitoring by means of feature extraction, selection and modeling for $\mathrm{Al}$ alloy. Mechanical Systems and Signal Processing, 60-61, 151-165. https://doi.org/10.1016/j.ymssp.2014.12.021

[17] Pal, K., Bhattacharya, S., \& Pal, S. K. (2010). Multisensorbased monitoring of weld deposition and plate distortion for various torch angles in pulsed MIG welding. J. Adv. Manuf. Technol., 50(5-8), 543-556. https://doi.org/10.1007/s00170-010-2523-8

[18] Graz, L., Grum, J., Polajnar, I., \& Slabe, J. M. (2004). Feasibility study of acoustic signals for on-line monitoring in short circuit gas metal arc welding. International Journal of Machine Tools \& Manufacture, 44(5), 555-561. https://doi.org/10.1016/j.jimachtools.2003.10.016

[19] Hastie, T., Tibshirani, R., \& Friedman, J. (2009). The Elements of Statistical Learning Data Mining, Inference, and Prediction. Stanford, California: Springer Science \& Business Media.

[20] Wang, W., Xu, Z., Lu, W., \& Zhang, X. (2003). Determination of the spread parameter in the Gaussian kernel for classification and regression. Neurocomputing, 55(3-4), 643-663. https://doi.org/10.1016/S0925-2312(02)00632-X

[21] Pal, K., Bhattacharya, S., \& Pal, S. K. (2009). Prediction of metal deposition from arc sound and weld temperature signatures in pulsed MIG welding. Int. J. Adv. Manuf. Technol., 45, 1113-1130. https://doi.org/10.1007/s00170-009-2052-5 


\section{Contact information:}

Dejan MARIĆ, Mag. ing. mech., Assistant

Mechanical Engineering Faculty in Slavonski Brod,

Josip Juraj Strossmayer University of Osijek,

Trg Ivane Brlić Mažuranić 2, HR-35000 Slavonski Brod,

Republic of Croatia

E-mail: dmaric@sfsb.hr

Miroslav DUSPARA, PhD, Assistant Professor

Mechanical Engineering Faculty in Slavonski Brod,

Josip Juraj Strossmayer University of Osijek,

Trg Ivane Brlić Mažuranić 2, HR-35000 Slavonski Brod,

Republic of Croatia

E-mail: mduspara@sfsb.hr

Tomislav ŠoLIć, Mag. ing. mech., Assistant

Mechanical Engineering Faculty in Slavonski Brod,

Josip Juraj Strossmayer University of Osijek,

Trg Ivane Brlić Mažuranić 2, HR-35000 Slavonski Brod,

Republic of Croatia

E-mail: tsolic@sfsb.hr

Ivan SAMARDŽIĆ, PhD, Professor with Tenure

Mechanical Engineering Faculty in Slavonski Brod,

Josip Juraj Strossmayer University of Osijek,

Trg Ivane Brlić Mažuranić 2, HR-35000 Slavonski Brod,

Republic of Croatia

E-mail: isamardzic@sfsb.hr 